\title{
Nişasta Nanokristali Üretimi ve Karakterizasyonu
}

\author{
Ayşe Korkut ${ }^{1}$, Kevser Kahraman ${ }^{2 *}$ \\ ${ }^{1}$ Abdullah Gül Üniversitesi, Fen Bilimleri Enstitüsü, İleri Malzemeler ve Nanoteknoloji Anabilim Dalı, Kayseri, Türkiye (ORCID: 0000-0002-8823-2089) \\ ${ }^{2 *}$ Abdullah Gül Üniversitesi, Malzeme Bilimi ve Nanoteknoloji Mühendisliği, Kayseri, Türkiye (ORCID: 0000-0002-2786-3944)
}

(İlk Geliş Tarihi 28 Eylül 2019 ve Kabul Tarihi 27 Ekim 2019)

(DOI:10.31590/ejosat.626229)

ATIF/REFERENCE: Korkut, A., \& Kahraman, K. (2019). Nişasta Nanokristali Üretimi ve Karakterizasyonu. Avrupa Bilim ve Teknoloji Dergisi, (17), 471-476.

\section{$\ddot{O} \mathbf{z}$}

$\mathrm{Bu}$ çalışmada nano malzeme üretimi konusunda doğal ve yenilenebilir bir kaynak olarak son yıllarda oldukça ilgi çeken bir hammadde olan nişastadan yüksek kristaliniteye sahip nanokristal üretimi hedeflenmiştir. Bu amaçla buğday nişastası farklı oranlarda $\mathrm{H}_{2} \mathrm{SO}_{4}$ (1:2 ve 1:4 nişasta:asit) ile beş gün boyunca $50^{\circ} \mathrm{C}$ sıcaklıkta hidroliz edilmiştir. Hidroliz sonrasında örnekler diyalize tabi tutularak safsızlıklar giderilmiş, liyofilize edilerek kurutulmuştur. Elde edilen nişasta nanokristalleri taramalı elektron mikroskobu (SEM) kullanılarak boyut; X-Işını Kırınım Spektroskopisi (XRD) kullanılarak yapı ve kristalinite; Fourier dönüşümlü kızılötesi spektrometresi (FT-IR) kullanılarak yapı açısından karakterize edilmiştir. Doğal haldeki buğday nişastası da aynı şekilde karakterize edilmiş ve hidroliz işleminin yapı, boyut ve kristalinite üzerine etkisi incelenmiştir.

SEM görüntüleri incelendiğinde buğday nişastasının boyutlarının 5-10 $\mu \mathrm{m}$ arasında değişim gösterdiği belirlenmiştir. Asit hidrolizi sonucunda ise nişasta boyutunun oldukça azaldığı ve 50 nm'nin altına düştüğü gözlenmiştir. Doğal haldeki buğday nişastası birbirinden bağımsız granüller halinde iken nişasta nanokristalleri kümeleşmiş halde görüntülenmiştir. XRD desenleri incelendiğinde asit hidrolizi ile elde edilen nişasta nanokristallerin buğdayın tipik X-1şını kırınım deseni olan A-tipi X-1şını kırınım desenini verdiği gözlenmiştir. X-1şını kırınım desenleri yapı açısından incelendiğinde işlem görmemiş doğal haldeki buğday nişastası ile nişasta nanokristallerin arasında fark görülmese de, bu örneklerin kristalinite indeks değerlerinin farklı olduğu belirlenmiştir. Doğal haldeki buğday nişastasının kristalinite indeks değeri \%42,2 olarak belirlenmişken, asit hidrolizi ile üretilen nişasta nanokristallerinin kristalinite indeks değerleri daha yüksek bulunmuştur. Düşük oranda asit kullanılarak üretilen nişasta nanokristalinin (1:2) kristalinite indeks değeri \%57,3 iken daha yüksek oranda kullanılarak üretilen nişasta nanokristalininin (1:4) kristalinite indeks değeri \%68,5 olarak belirlenmiştir. FT-IR sonuçlarına göre ise nişasta nanokristallerin doğal buğday nişastası ile aynı yapıya sahip olduğu gözlemlenmiştir.

Anahtar kelimeler: Buğday nişastası, nişasta nanokristali, kristalinite, XRD, SEM, FT-IR

\section{Production and Characterization of Starch Nanocrystal}

\begin{abstract}
In this study, it is aimed to produce high crystallinity nanocrystals from starch which is a very interesting raw material in recent years as a natural and renewable resource in nano material production. For this purpose wheat starch was acid hydrolyzed using different amount of acid (starch: $\mathrm{H}_{2} \mathrm{SO}_{4}$ ratio; $1: 2$ and 1:4) at $50^{\circ} \mathrm{C}$ temperature for 5 days. After hydrolysis, samples were dialyzed to remove impurities and freze-dried. Native wheat starch and nanocrystals were characterized by using scanning electron microscope (SEM); X-Ray diffaction spectroscopy (XRD) and Fourier Transform Infrared Spectrometer (FT-IR) in terms of size, crystallinity and structure, respectively. Native wheat starch was also characterized as control and the effect of hydrolysis on size, crystalinity and structure.
\end{abstract}

According toSEM images, it can be observed that the size of native wheat starch varied between 5-10 $\mu \mathrm{m}$. It was observed that the size of starch granule decreased considerably as a result of acid hydrolysis. The size of wheat starch granule decreased below the 50

\footnotetext{
*Sorumlu Yazar: Abdullah Gül Üniversitesi, Malzeme Bilimi ve Nanoteknoloji Mühendisliği, Kayseri, Türkiye, ORCID: 0000-0002-2786-3944, kevser.kahraman@agu.edu.tr
} 
$\mathrm{nm}$ due to the hydrolysis procedure. While native starch granules were observed as independent granules, starch nanocrystals located as aggregates. According to the XRD patterns, it was observed that the starch nanocrystals obtained by acid hydrolysis gave the Atype X-ray diffraction pattern, which is the typical X-ray diffraction pattern of wheat. While there was no difference between X-ray diffraction patterns between native wheat starch and starch nanocrystals in terms of structure, there was a considerable difference between crystallinity index values of these samples. The starch nanocrystals produced by acid hydrolysis had higher crystallinity index values when compared with its corresponding which had $42.2 \%$ crystallinity. The crystallinity index value of starch nanocrystals produced by using low acid ratio (1:2) was $57.3 \%$, whereas the crystallinity index value of starch nanocrystalline produced by using higher acid ratio (1:4) was determined as $68.5 \%$. According to FT-IR results, it was observed that starch nanocrystals have the same structure as native wheat starch.

Keywords: Wheat starch, starch nanocrystals, crystallinity, XRD, SEM, FT-IR

\section{Giriş}

Fosil enerji kaynaklarının tükenmesi ve artan çevresel kaygılar birçok alanda yenilenebilir ve sürdürülebilir petrol dışı kaynaklardan üretilmiş ürünlere olan talebi arttırmıştır. Bu durum yenilikçi ve verimli malzemelerin gelişmesine olanak sağlayan nanoteknoloji ile çevre dostu hammaddelerin kullanımına olanak sağlayan biyomalzeme üretimi gibi iki alanın biraraya gelmesine öncü olmuştur. Nanoteknoloji günümüzde bilişim, güvenlik, tıp, kozmetik, enerji, tekstil, çevre ve gıda gibi pek çok sektörde uygulama alanı bulan ve endüstriyel anlamda ürün iyileştirmesine yönelik Ar-Ge çalışmalarında kullanılan bir alandır. Doğada yaygın olarak bulunan, yenilenebilir, biyobozunur ve toksik olmayan bir materyal olan nişasta, nanomalzeme üretimi konusunda son yıllarda oldukça ilgi çekmektedir. Nişasta polimeri, asit hidrolizi, enzimatik hidroliz, yüksek basınç homojenizasyonu, ultrasonikasyon, reaktif ekstrüzyon, gamma irradyasyon ve nanopresipitasyon gibi yöntemler kullanılarak nanoboyuta indirgenmektedir (Hélène Angellier vd., 2004; Kim, Park ve Lim, 2015; Liu vd., 2009; Sun vd., 2014).

Nişasta, doğada yaygın olarak bulunan ve bitkilerin fotosentez yoluyla elde ettikleri enerjiyi depolamak için sentezledikleri bir biyopolimerdir. Birçok gıda maddesinin de temel bileşeni olan nişasta, insan beslenmesinde büyük bir önem taşımasının yanı sıra gıdaların fiziksel özellikleri (jel oluşturma, kıvam verme, su tutma, vb.) üzerindeki etkisi nedeniyle de oldukça önemlidir. Nişasta $\alpha$ D-glukoz birimlerinin polimerleşmesinden oluşan bir polisakkarittir ve kimyasal yapısında lineer bir polimer olan amiloz ve dallanmış bir polimer olan amilopektin bulunmaktadır (Šárka ve Dvořáček, 2017).

Nişasta kaynağı ve amiloz içeriğinin, nişasta nanokristallerin morfolojisi üzerine olan etkisinin incelendiği bir çalışmada, normal amiloz içerikli mısır nişastası, yüksek amiloz içerikli mısır nişastası, mumsu (\%100 amilopektin) mısır nişastası, patates ve buğday nişastası kullanılarak nişasta nanokristalleri üretilmiştir. Nişastanın kaynağı, nanokristallerin boyutları üzerinde önemli bir etki göstermezken nanokristallerin şekil ve kristaliniteleri açısından farklılığa neden olmuştur. (Lecorre, Bras ve Dufresne, 2012). Nanokristal üretim metodu da nanokristallerin şekil ve boyutları üzerinde farklılığa sebep olan bir diğer etkendir (Dai vd., 2018). Mumsu mısır nişastası kullanılarak yapılan çeşitli çalışmalarda farklı boyutlarda nanokristaller elde edilmiştir. Mumsu mısır nişastası kullanıldığında 20-40 nm (Putaux vd. 2003), <40 nm (Kim, Park ve Kim 2017) , 70- 100 nm (Namazi ve Dadkhah, 2010) ve 50-130 $\mathrm{nm}$ (Romdhane vd. 2015) boyut aralığında nişasta nanokristaller elde edilmiştir.

Nişasta nanokristallerinin geniş yüzey alanına sahip olmaları ve yapılarında bulunan hidroksil gruplarının oldukça reaktif olması nedeniyle kompozit bileşeni, emülsiyon stabilizatörü, yağ ikame edicisi, ambalaj materyali, ilaç taşıyıcısı, atıksu arıtımında adsorber, kağıt üretiminde bağlayıcı olarak kullanımı ile ilgili birçok alanda uygulamaya sahiptir (Kim, Park ve Lim, 2015; Dai, Zhang ve Cheng, 2019). Doğal ve yenilenebilir bir kaynak olan nişastanın nano malzeme üretimi konusunda son yıllarda ilgi çeken bir materyal olması nedeniyle, bu çalışmada buğday nişastası kullanılarak yüksek kristaliniteye sahip nanokristal üretimi hedeflenmiştir. Bu amaçla buğday nişastası nişasta:asit oranı farklı olacak şekilde $\mathrm{H}_{2} \mathrm{SO}_{4}$ ile muamele edilerek nanokristal üretilmiştir. Üretilen nanokristaller boyut (taramalı elektron mikroskobu, SEM), kristalinite ve yapı (X-Işını Kırınım Spektroskopisi, XRD) ve yapı (Fourier dönüşümlü kızılötesi spektrometresi, FT-IR) açısından karakterize edilmiştir.

\section{Materyal ve Metot}

\subsection{Materyal}

Buğday nişastası MGP Ing. (ABD)’den temin edilmiştir. Çalışmada kullanılan tüm kimyasallar analitik saflıktadır.

\subsection{Nişasta Nanokristallerinin Üretimi}

Nişasta nanokristallerinin üretimi asit hidrolizi yöntemi kullanılarak gerçekleştirilmiştir. Bu amaçla literatürde Xu vd. (2010)'nin belirttiği yöntem kullanılmıştır. Bu kapsamda $20 \mathrm{~g}$ buğday nişastası 1:2 (g/ml) ve 1:4 (g/ml) oranlarında $\mathrm{H}_{2} \mathrm{SO}_{4}\left(3,16 \mathrm{M}, \mathrm{Sigma}_{\text {, }}\right.$ ABD) ile karıştırılmıştır. Hidroliz işlemi $50^{\circ} \mathrm{C}$ sabit sıcaklıkta 5 gün boyunca sürekli karıştırılarak (Heidolph, Almanya, $300 \mathrm{rpm}$ ) gerçekleştirilmiştir. Süre sonunda karışım NaOH (5M, Merck, Almanya) ile nötralize edilerek hidroliz sonlandırılmıştır. Nötralize edilen süspansiyon $5.000 \mathrm{rpm}$ hızda 10 dakika süre ile santrifüj edilerek (Hettich Rotina 380R, Almanya) oluşan çökelti süpernatanttan ayrılmıştır. İçerisinde nişasta nanopartikülleriyle birlikte asit kalıntıları ve tuz gibi maddelerde bulunan çökelti, 
saflaştırılmak amacı ile diyaliz işlemine tabi tutulmuştur. Diyaliz işlemi oda sıcaklığında 3 gün uygulanmıştır (3.500Da, Thermo Scientific, ABD). Diyaliz işleminin ardından örnekler liyofilize edilerek kurutulmuştur.

\subsection{Nişasta Nanopartiküllerin Karakterizasyonu}

\subsubsection{Taramalı Elektron Mikroskobu (SEM)ile Karakterizasyon}

Nişasta nanopartiküllerinin ve işlem görmemiş buğday nişastasının yüzey morfolojisi, yapısal karakterizasyonu ve boyut ile ilgili bilgi almak için Xie vd. (2016)'nin belirttiği gibi taramalı elektron mikroskobu (SEM, Zeiss Leo 440, Almanya) kullanılmıştır. SEM analizi ile örneklerin boyutları ve yapısında meydana gelen değişimler incelenmiştir. Örnekler $105^{\circ} \mathrm{C}$ 'de 24 saat kurutulduktan sonra, ölçüm öncesi vakumlu püskürtmeli kaplayıcı kullanılarak altın ile kaplanmıştır. Karakterizasyonu yapılacak örneklerin ölçümü 3 kV altında yapılmıştır.

\subsubsection{X-Işını Kırınım Spektroskopisiile Karakterizasyon}

Nişasta nanopartiküllerinin ve işlem görmemiş buğday nişastasının kristal yapıları X-Işını kırınım spektroskopisi (Bruker AXS D8 advance model, Almanya) kullanılarak, Xie vd. (2016)'nin belirttiği yönteme göre incelenmiştir. Ölçümler $40 \mathrm{kV}$ ve $30 \mathrm{~mA}$ 'de difraktometre $(\mathrm{Cu} \mathrm{K \alpha}, \lambda=1,54 \mathrm{~A})$ kullanılarak gerçekleştirilmiştir. Difraktometre konumu $2 \Theta=5-40^{\circ}$ aralığında ayarlanmıştır. Numunelerin kristalinite indeks değerleri cihazın yazılımı kullanılarak aşağıdaki eşitlik ile hesaplanmıştır;

$$
\text { Kristalinite }(\%)=\frac{\mathrm{I}_{002}-\mathrm{I}_{\mathrm{am}}}{\mathrm{I}_{002}} \times 100
$$

Bu eşitlikte $\mathrm{I}_{002} ; 2 \Theta=22,1^{\circ}$ 'deki kırınım yoğunluğunu, $\mathrm{I}_{\mathrm{am}}$ ise $2 \Theta=18^{\circ}$ 'deki kırınım yoğunluğunu ifade etmektedir.

\subsubsection{Fourier Dönüşümli Kızılötesi Spektroskopisi (FT-IR) ile Karakterizasyon}

Nişasta nanopartiküllerinin ve işlem görmemiş buğday nişastasının yapısal özellikleri Fourier Dönüşümlü Kızılötesi Spektrometresi (FT-IR, Thermo Nicolet Avatar 370, ABD) kullanılarak karakterize edilmiştir. Ölçümler $4.000-400 \mathrm{~cm}^{-1}$ dalga boyu aralığında gerçekleştirilmiş ve her örnek 32 kez taranmıştır (Xie vd., 2016).

\section{Araştırma Sonuçları ve Tartışma}

\subsection{Taramalı Elektron Mikroskobu (SEM)}

İşlem görmemiş buğday nişastası ve farkl $\mathrm{H}_{2} \mathrm{SO}_{4}$ oranlarıyla hidroliz işlemine tabi tutularak elde edilen nişasta nanokristallerin SEM görüntüleri Şekil 1'de gösterilmiştir. İşlem görmemiş buğday nişastası granülleri farklı büyüklüklere sahip küreler halinde görüntülenmiştir. Bu granüllerin büyüklükleri genel olarak 5 ila $10 \mu \mathrm{m}$ arasında değişim göstermektedir. Buğday nişastasının granül büyüklüğü literatür verileri ile uyumludur. Martens vd. (2018) de buğday nişastasının granül çapını $20 \mu \mathrm{m}$ olarak tespit etmiştir.

$\mathrm{Bu}$ çalışma kapsamında buğday nişastasının asit ile hidroliz edilmesi ile elde edilen nişasta nanokristallerinin büyüklükleri ise $<50 \mathrm{~nm}$ olarak gözlenmiştir. Literatürde yapılan çalışmalarda da nişasta nanokristallerin boyutları buğday nişastasına kıyasla oldukça düşük (<200 nm) bulunmuştur (Kim vd., 2012; Pereda ve Dufresne, 2014).

Şekil 1'den de görüleceği üzere doğal haldeki buğday nişastası granülleri birbirinden bağımsız olarak bulunurken, nişasta nanokristalleri kümeleşmiş granüller halinde bulunmaktadır. Nişasta nanokristallerin kümeler halinde bulunması literatürde de birçok çalışmada gözlenmiştir (Saeng-on ve Aht-Ong, 2017). Nişasta nanokristallerin bu şekilde kümeleşmesinin nedeni olarak, nanokristallerin yüzeyinde bulunan hidroksil gruplarının birbirleriyle etkileşimi sonucu oluşan yeni hidrojen bağları gösterilmiştir (Mariano vd., 2017). Buğday nişastasının farklı oranlarda hidroliz işlemine tabi tutulmasıyla elde edilen nanokristaller arasında ise şekil ve büyüklük açısından önemli bir faklılık gözlenmemiştir. 

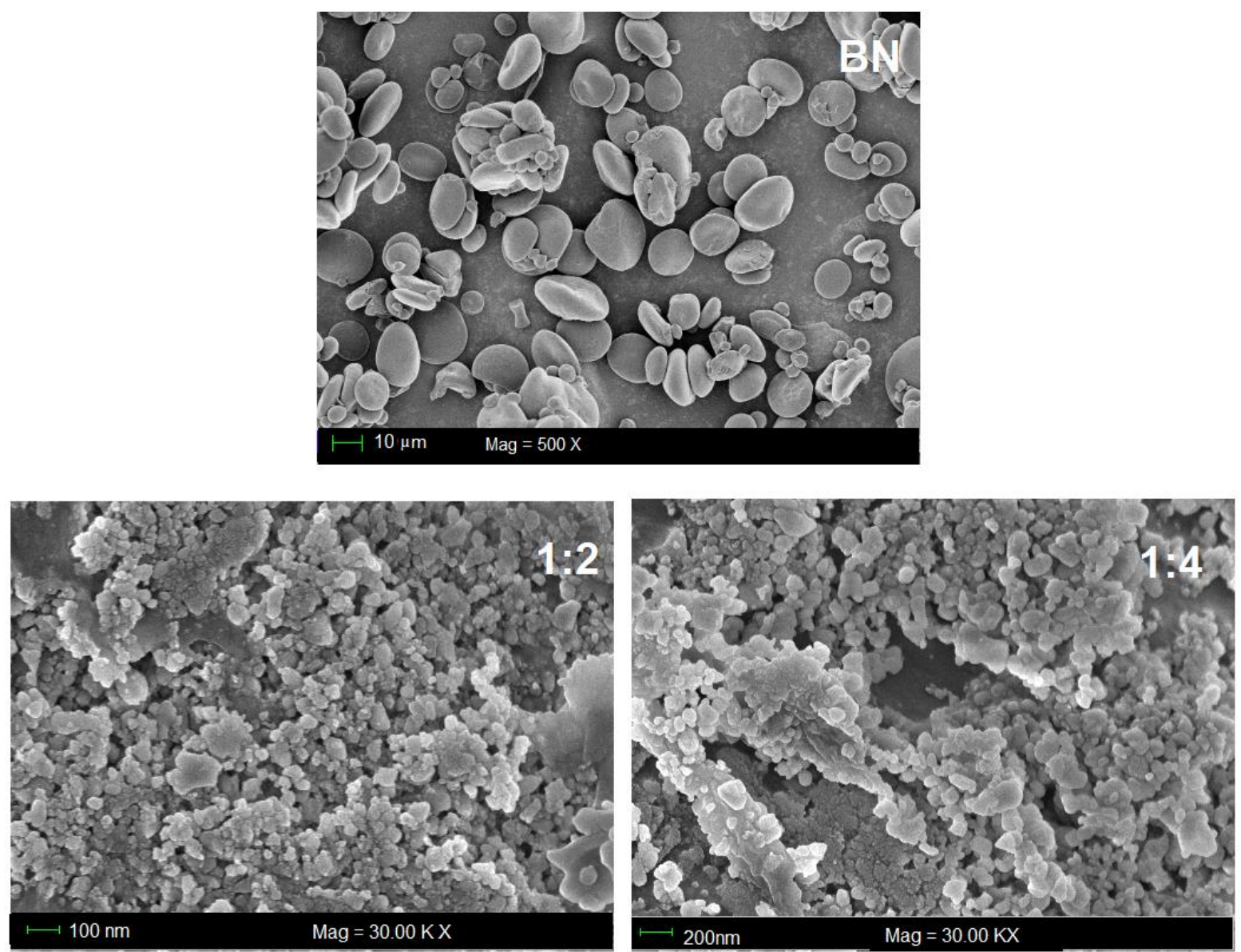

Şekil 1: Nişasta örneklerinin taramalı elektron mikroskobu (SEM) görüntüleri. BN; işlem görmemiş doğal haldeki buğday nişastasl, 1:2 ve 1:4; Hidrolizde kullanılan nişasta $(\mathrm{g}): \mathrm{H}_{2} \mathrm{SO}_{4}(\mathrm{ml})$ oranı

\subsection{X-Işını Kırınım Spektroskopisi (XRD)}

Nişasta nanokristallerinin ve bunların işlem görmemiş formu olan buğday nişastasının X-ışını kırınım desenleri Şekil 2'de gösterilmiştir. X-ışını kırınım desenleri incelendiğinde her üç örnekte de $2 \Theta=23.01^{\circ}, 17.13^{\circ}$ ve $15.09^{\circ}$ noktalarında belirgin pikler gözlenmektedir.

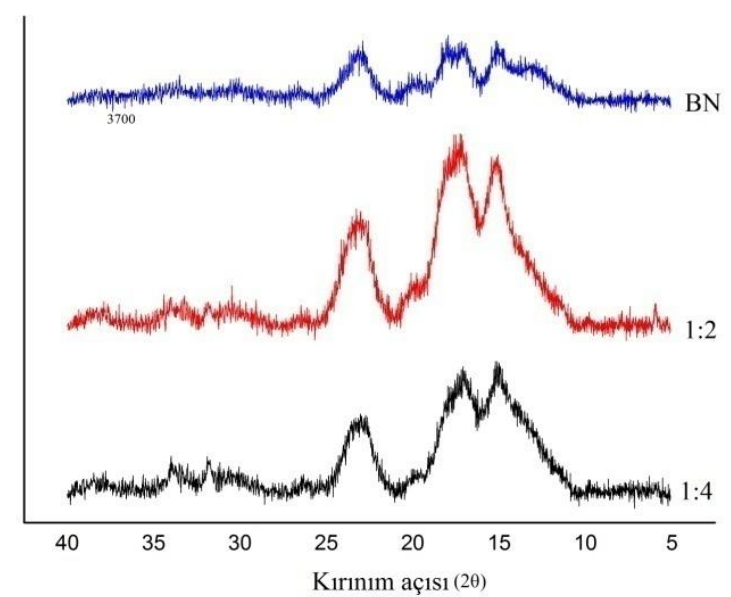

Şekil 2: Nişasta Örneklerinin X-Işını Kırınım (XRD) Desenleri. BN; işlem görmemiş doğal haldeki buğday nişastası, 1:2 ve 1:4; Hidrolizde kullanılan nişasta $(\mathrm{g}): \mathrm{H}_{2} \mathrm{SO}_{4}(\mathrm{ml})$ oranı

Normal buğday nişastası ve üretilen nanokristallerin yapısal olarak değişim göstermediği görülmekle birlikte, kristalinite indeks değerleri arasında farklılıklar belirlenmiştir. Buğday nişastasının kristalinite indeks değeri \%42,2 olarak hesaplanmışken, nanokristallerin kristalinite indeks değerleri daha yüksek bulunmuştur. 1:2 oranında $\mathrm{H}_{2} \mathrm{SO}_{4}$ kullanılarak hidrolize edilen örneğin 
kristalinite indeks değeri \%57,3 iken 1:4 oranında $\mathrm{H}_{2} \mathrm{SO}_{4}$ kullanılarak hidrolize edilen örneğin kristalinite indeks değeri \% 08,5 olarak bulunmuştur. Nişasta granülündeki kristal bölgeler amorf bölgelere göre asit hidrolizine daha dirençlidir. Bu yüzden nişasta içerisindeki kristal kısımlar seyreltik sülfürik ya da hidroklorik asit varlığında izole edilebilir (Kim, Park ve Lim, 2015). Bu çalışmada seyreltik $\mathrm{H}_{2} \mathrm{SO}_{4}$ ile gerçekleştirilen asit hidrolizi seçici olarak amorf bölgelere etki etmiş ve yüksek kristalinitede nişasta nanokristaller elde edilmiştir.

Nişasta kristal yapısına göre A, B ve C olmak üzere üç gruba ayrılmaktadır (Cheetham ve Tao, 1998). A tipi kristal forma sahip nişastalar genel olarak hububat kökenli olup X-1şıı kırınım deseninde $2 \Theta=15^{\circ}, 17^{\circ}, 18^{\circ}$ ve $23^{\circ}$ de belirgin pikler vererek kendilerine özgü yapıyı oluşturmaktadırlar (Kim vd., 2012, Martens vd., 2018). Bu çalışmada kullanılan buğday nişastası ve üretilen nanokristaller de buğday nişastasının literatürde belirtilen tipik X-1şını kırınım deseni $2 \Theta$ değerlerine sahiptir.

\subsection{Fourier Dönüşümlü Kızllötesi Spektrometresi (FT-IR)}

İşlem görmemiş doğal haldeki buğday nişastası ve nişasta nanokristallerin FT-IR spektrumları Şekil 3'te gösterilmiştir. FT-IR spektrumlarında 3.300 ile $3.750 \mathrm{~cm}^{-1}$ bandındaki bölge $-\mathrm{OH}$ bağlarının bulunduğu bölgedir (León vd., 2017) ve bu pik nişasta içerisindeki serbest su varlığını göstermektedir. Doğal haldeki buğday nişastası ve nişasta nanokristallerin her birinde $2.963 \mathrm{~cm}^{-1}$ 'de keskin pik bulunmaktadır. Bu bölge $-\mathrm{C}-\mathrm{H}$ bağlarının varlığını işaret etmektedir. İkinci tepe noktası $1.583 \mathrm{~cm}^{-1}$ noktasında gözlemlenmişken üçüncü pik $1.242 \mathrm{~cm}^{-1}$ bandındadır. Nişasta nanokristallerin doğal muadiliyle aynı absorbsiyon bantlarında pik vermesi, hidroliz sonrası doğal yapının korunduğunu göstermektedir.

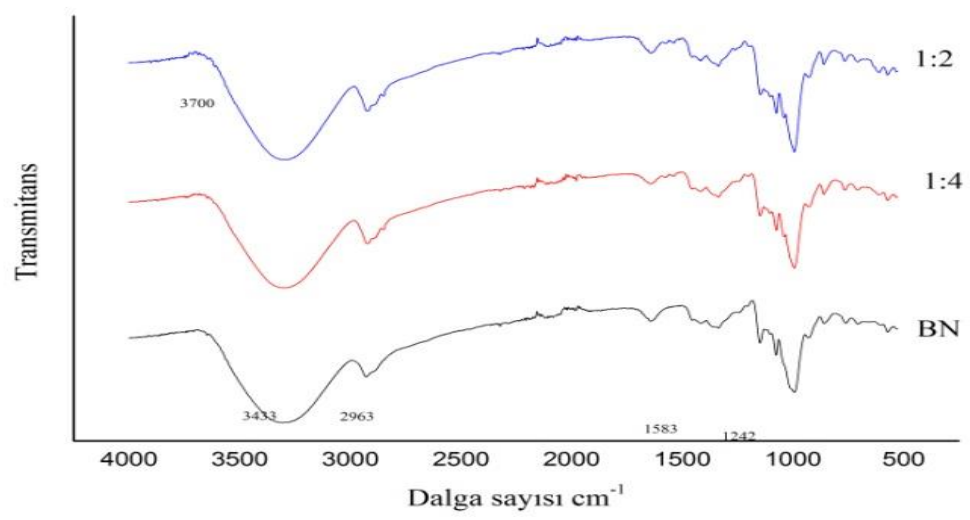

Şekil 3: Fourier Dönüşümlü Klzılötesi Spektrometresi (FT-IR) Spektrumları. BN; İşlem görmemiş doğal haldeki buğday nişastası, 1:2 ve 1:4; Hidrolizde kullanılan nişasta $(\mathrm{g}): \mathrm{H}_{2} \mathrm{SO}_{4}(\mathrm{ml})$ oranı

\section{Sonuç}

$\mathrm{Bu}$ çalışma kapsamında buğday nişastası, iki farklı oranda (1:2 ve 1:4, nişasta:asit) $\mathrm{H}_{2} \mathrm{SO}_{4}$ ile hidroliz işlemine tabi tutularak nişasta nanaokristalleri üretilmiştir. Doğal buğday nişastası ile elde edilen nişasta nanokristaller boyut, yapı ve kristalinite değerleri

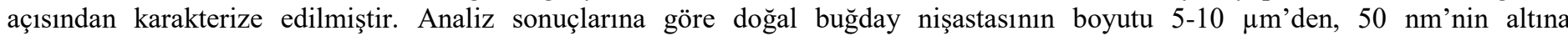
düşürülmüştür. Kullanılan asit oranlarının farklı olması nişasta nanokristallerinin boyutunda önemli değişikliğe neden olmamıştır. Her iki nanokristal örnek de SEM görüntüsünde kümeleşmiş halde bulunarak benzer özellikler sergilemiştir. Nişasta nanokristalleri kristalinite açısından değerlendirildiklerinde ise, doğal buğday nişastasından ( $\% 42,2$ kristal) daha yüksek kristalinite indeks değerlerine sahip oldukları gözlemlenmiştir.1:4 (nişasta:asit) oranında asit kullanılarak üretilen nişasta nanokristal örneğinin kristalinite indeks değeri \%68,5 iken, 1:2 (nişasta:asit) oranında asit kullanılarak üretilen örneğin kristalinite indeks değeri $(\% 57,3)$ daha düşük bulunmuştur.İ̧slem görmemiş doğal buğday nişastası ile asit hidrolizi sonucu üretilen nişasta nanokristalleri aynı noktalarda pikler verecek şekilde FT-IR deseni oluşturmuşlardır. Bu durum da hidroliz işleminin nişasta örneklerinin yapısı üzerinde değişikliğe neden olmadığını göstermektedir. Bu çalışma kapsamında nanomalzeme üretimi konusunda ilgi çekici bir kaynak olan nişastadan yüksek kristaliniteye sahip nanoboyutlu nanokristal üretimi gerçekleştirilmiştir. Elde edilen veriler nanokristaller kullanılarak yapılacak olan çeşitli çalışmalara ışık tutma niteliğindedir.

\section{Kaynakça}

Cheetham, N. W. H., ve Tao, L. (1998). Variation in crystalline type with amylose content in maize starch granules: An X-ray powder diffraction study. Carbohydrate Polymers, 36(4), 277-284. doi.org/10.1016/S0144-8617(98)00007-1

Dai, L., Li, C., Zhang, J., ve Cheng, F. (2018). Preparation and characterization of starch nanocrystals combining ball milling with acid hydrolysis. Carbohydrate Polymers, 180(September 2017), 122-127. doi.org/10.1016/j.carbpol.2017.10.015

Dai, L., Zhang, J., ve Cheng, F. (2019). Succeeded starch nanocrystals preparation combining heat-moisture treatment with acid hydrolysis. Food Chemistry, 278(September 2018), 350-356. doi.org/10.1016/j.foodchem.2018.11.018 
Hélène Angellier, Luc Choisnard, Sonia Molina-Boisseau, Patrick Ozil, ve Alain Dufresne, ll. (2004). Optimization of the Preparation of Aqueous Suspensions of Waxy Maize Starch Nanocrystals Using a Response Surface Methodology. Biomacromolecule, 5, 41, 545-1551. doi.org/10.1021/BM049914U

Kim, H.-Y., Lee, J. H., Kim, J.-Y., Lim, W.-J., ve Lim, S.-T. (2012). Characterization of nanoparticles prepared by acid hydrolysis of various starches. Starch - Stärke, 64(5), 367-373. doi.org/10.1002/star.201100105

Kim, H.-Y., Park, S. S., ve Lim, S.-T. (2015). Preparation, characterization and utilization of starch nanoparticles. Colloids and Surfaces B: Biointerfaces, 126, 607-620. doi.org/10.1016/J.COLSURFB.2014.11.011

Kim, H. Y., Lee, J. H., Kim, J. Y., Lim, W. J., ve Lim, S. T. (2012). Characterization of nanoparticles prepared by acid hydrolysis of various starches. Starch/Staerke, 64(5), 367-373. doi.org/10.1002/star.201100105

Kim, J. H., Park, D. H., ve Kim, J.-Y. (2017). Effect of heat-moisture treatment under mildly acidic condition on fragmentation of waxy maize starch granules into nanoparticles. Food Hydrocolloids, 63, 59-66. doi.org/10.1016/J.FOODHYD.2016.08.018

Lecorre, D., Bras, J., ve Dufresne, A. (2012). Influence of native starch's properties on starch nanocrystals thermal properties. Carbohydrate Polymers, 87(1), 658-666. doi.org/10.1016/j.carbpol.2011.08.042

León, A., Reuquen, P., Garín, C., Segura, R., Vargas, P., Zapata, P., ve Orihuela, P. A. (2017). FTIR and raman characterization of $\mathrm{TiO} 2$ nanoparticles coated with polyethylene glycol as carrier for 2-methoxyestradiol. Applied Sciences (Switzerland), 7(1), 1-9. doi.org/10.3390/app7010049

Liu, D., Wu, Q., Chen, H., ve Chang, P. R. (2009). Transitional properties of starch colloid with particle size reduction from micro- to nanometer. Journal of Colloid and Interface Science, 339(1), 117-124. doi.org/10.1016/J.JCIS.2009.07.035

Mariano, M., Mukurumbira, A., Amonsou, E. O., Dufresne, A., ve Mellem, J. J. (2017). Microstructure, thermal properties and crystallinity of amadumbe starch nanocrystals. International Journal of Biological Macromolecules, 102, 241-247. doi.org/10.1016/j.ijbiomac.2017.04.030

Martens, B. M. J., Gerrits, W. J. J., Bruininx, E. M. A. M., ve Schols, H. A. (2018). Amylopectin structure and crystallinity explains variation in digestion kinetics of starches across botanic sources in an in vitro pig model. Journal of Animal Science and Biotechnology, 9(1), 1-13. doi.org/10.1186/s40104-018-0303-8

Namazi, H., ve Dadkhah, A. (2010). Convenient method for preparation of hydrophobically modified starch nanocrystals with using fatty acids. Carbohydrate Polymers, 79(3), 731-737. doi.org/10.1016/J.CARBPOL.2009.09.033

Pereda, M., ve Dufresne, A. (2014). Chapter 7: Starch Nanocrystals. Handbook of Green Materilas. Eds. Oksman, K., Mathew, A. P., Bismarck, A., Rojas, O. Sain, M.. World Scientific Pub Co Inc. doi.org/10.1142/9789814566469_0007

Putaux, J.-L., Molina-Boisseau, S., Momaur, T., ve Dufresne, A. (2003). Platelet Nanocrystals Resulting from the Disruption of Waxy Maize Starch Granules by Acid Hydrolysis. Biomacromolecules, 4(5), 1198-1202. doi.org/10.1021/bm0340422

Romdhane, A., Aurousseau, M., Guillet, A., ve Mauret, E. (2015). Cross flow microfiltration of starch nanocrystal suspensions. The Canadian Journal of Chemical Engineering, 93(2), 412-418. doi.org/10.1002/cjce.22092

Saeng-on, J., ve Aht-Ong, D. (2017). Production of starch nanocrystals from agricultural materials using mild acid hydrolysis method: Optimization and characterization. Polymers from Renewable Resources, 8(3), 91-116.

Šárka, E., ve Dvořáček, V. (2017). Waxy starch as a perspective raw material (a review). Food Hydrocolloids, 69, 402-409. doi.org/10.1016/j.foodhyd.2017.03.001

Sun, Q., Gong, M., Li, Y., ve Xiong, L. (2014). Effect of retrogradation time on preparation and characterization of proso millet starch nanoparticles. Carbohydrate Polymers, 111, 133-138. doi.org/10.1016/J.CARBPOL.2014.03.094

Xie, J., Hse, C., Hoop, C. F. De, Hu, T., Qi, J., ve Shupe, T. F. (2016). Isolation and characterization of cellulose nanofibers from bamboo using microwave liquefaction combined with chemical treatment and ultrasonication. Carbohydrate Polymers, 151, 725734. doi.org/10.1016/j.carbpol.2016.06.011

Xu, Y., Ding, W., Liu, J., Li, Y., Kennedy, J. F., Gu, Q., ve Shao, S. (2010). Preparation and characterization of organic-soluble acetylated starch nanocrystals. Carbohydrate Polymers, 80(4), 1078-1084. doi.org/10.1016/j.carbpol.2010.01.027 